\title{
Lansoprazole Associated Lymphocytic Colitis With Irritable Bowel Syndrome in a Patient Without Symptoms of Diarrhea
}

\author{
Nezih Piskinpasa ${ }^{\mathrm{a}, \mathrm{d}}$, Mehmet Emin Piskinpasa ${ }^{\mathrm{b}}$, Yasar Sertbas $^{\mathrm{c}}$
}

\begin{abstract}
We present a case of 64-year-old woman patient who developed microscopic colitis undergoing lansoprazole therapy for gastroesophageal reflux disease. Abdominal pain and mild weight loss had been developed. She had no symptoms of diarrhea. Appearance on colonoscopy was normal, but biopsies showed lymphocytic colitis. Lansoprazole therapy was ceased. A repeat colonoscopy 2 months after discontinuation revealed endoscopic and histological normalization.
\end{abstract}

Keywords: Microscopic colitis; Lansoprazole; Gastroesophageal reflux disease

\section{Introduction}

Microscopic colitis (MC) is characterized, clinically, by chronic or recurrent watery diarrhea without bleeding. There are well-defined histological findings and normal or nearly normal macroscopic findings on colonoscopy [1]. Collagenous colitis (CC) and lymphocytic colitis (LC) are the two major histological forms of MC. They have nearly the same clinical and macroscopical colonic mucosal findings $[2,3]$. Pathogenesis of MC is unknown $[4,5]$. The most widely postulated hypothesis is, the inflammatory disorders arising from epithelial immune responses to intraluminal dietary or bacterial contents, environmental risk factors such as drugs, have been suggested as a cause of this process, include non-steroidal anti-inflammatory drugs, simvastatin, selective seratonin reuptake inhibitors, acarbose, biphosphonates and proton pump inhibitors (PPIs) [6-9]. We report a case of lansoprazole-associated LC with

\section{Manuscript accepted for publication March 13, 2015}

aDepartment of Gastroenterology, Uskudar State Hospital, Istanbul, Turkey ${ }^{b}$ Department of Internal Medicine, Istanbul Training and Research Hospital, Istanbul, Turkey

'Department of Internal Medicine, Uskudar State Hospital, Istanbul, Turkey ${ }^{\mathrm{d} C}$ Corresponding Author: Nezih Piskinpasa, Altunizade Konutlari D Blok, Number 10, Kosuyolu, Istanbul, Turkey.

Email: nezihpiskinpasa@hotmail.com

doi: http://dx.doi.org/10.14740/jmc2099w a constipation dominant irritable bowel syndrome (IBS) as a concomitant disease.

\section{Case Report}

A 64-year-old woman with abdominal pain and mild weight loss was referred to a gastroenterologist. The patient fulfilled ROME III criteria. She presented a history of abdominal discomfort associated with improvement with defecation, constipation, bloating and gas for about 20 years but more frequent for the past 4 - 5 years. The patient reported receiving PO lansoprazole $30 \mathrm{mg} /$ day to treat gastroesophageal reflux disease for nearly 1 month. The medical history report also revealed that the patient was not receiving any concomitant medications or treatments at the time. After listening to the story of the patient and physical examination, complete blood count, erythrocyte sedimentation rate and biochemical tests were performed. An abdominal mass, hepatomegaly, fever, arthritis, dermatitis or signs of malabsorption were not found on physical examination; there were not abnormalities on initial laboratory tests including anemia, thyroid dysfunction, increased sedimentation rate, leukocytosis, presence of occult blood in stool or other abnormal biochemical findings. The patient had negative results on serological tests for coeliac disease (transglutaminase and endomysial antibody) and normal serum IgA levels. In pa-

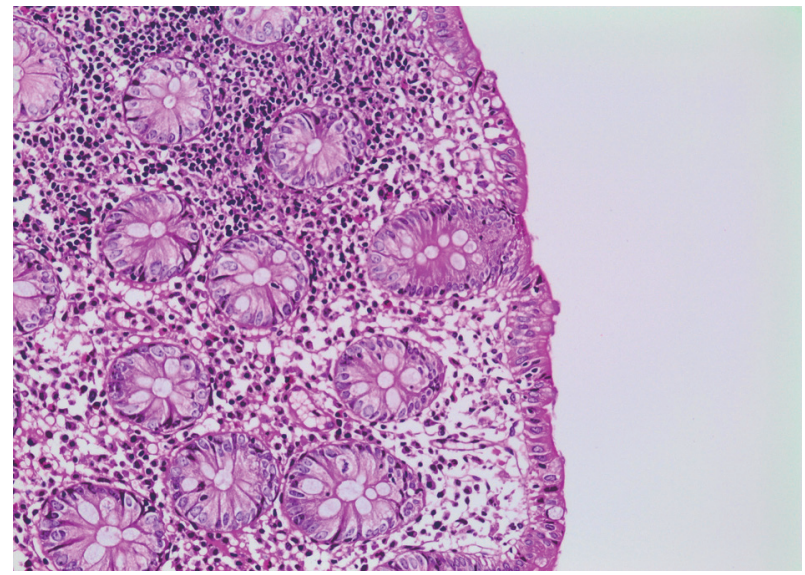

Figure 1. There are intraepithelial lymphocytosis and increased level of lymphoplasmositer cells in the lamina propria (H\&E, × 200). 
tient with the alarm signs such as weight loss, advanced age of onset, family history (cancer), colonoscopy was done. Appearance on colonoscopy was normal, but biopsies showed LC (Fig. 1). Lansoprazole therapy was ceased. Eight weeks later, endoscopic and histological normalization was ascertained.

\section{Discussion}

$\mathrm{MC}$ is regarded as a common cause of chronic watery diarrhea, accounting for approximately $4-13 \%$ of patients presenting with this symptoms [10]. LC and CC are the two major subtypes of MC with increasing prevalence of $10-15.7 / 100,000$ and 14.4/100,000 [10-13]. Increased awareness of the disease among clinicians and increased use of several drugs that cause $\mathrm{MC}$ are some of the causes of more frequent diagnosis. Since the growing incidence of $\mathrm{MC}$ seems to parallel the rise in the use of PPIs, it is essential to understand the association between MC and PPIs. A recent study from Netherlands found that $11.8 \%$ of the population had at least one prescription for PPIs in 1 year [14].

Initially, lansoprazole has been found to be associated with MC [8]. The frequency of lansoprazole-associated MC is unknown, at least $0.7 \%$ was found to develop $\mathrm{MC}$ [15]. There are several studies which further highlight the association between the PPIs and MC. Most common mechanisms are inhibition of colonic proton pumps which affect the local electrolyte balance, induction of smooth muscle relaxation that inhibit contractile activity, increased paracellular permeability and alteration of intestinal microbial flora [16-18].

Almost all the studies lansoprazole associated with $\mathrm{MC}$ are mentioning the watery diarrhea and normal or nearly normal macroscopic colonic mucosa. There are some studies designed as a retrospective analysis of colonic biopsies show that $\mathrm{LC}$ or $\mathrm{CC}$ were not confined to the patients just with diarrhea as a presenting symptom, but were also present with normal bowel movements and constipation. Wang et al mentioned 12 patients fulfilled the histological criteria but not the clinical criteria for classic LC and classified them as having atypical LC [19]. Nooroudien et al retrospectively reviewed non-malignant colon mucosal biopsies with 20 cases of LC, and mentioned the most common presenting complaints of them were chronic diarrhea in $9 / 20$ cases, abdominal pain in $7 / 20$ and constipation in $3 / 20$ [1]. Neal et al studied clinicopathological association and prevalence of LC in 100 asymptomatic, non-gluten sensitive adults who underwent screening surveillance colonoscopy for previous colonic polyps as a control group without a clinical symptom, and none had abdominal pain, weight loss or altered bowel habits. Of the 100 asymptomatic patients $4 \%$ had classic LC with no clinical symptoms [20]. One recent study to investigate the incidence of LC in patients with Hashimoto's thyroiditis found that 20 of 50 patients had LC. Only five of the patients had diarrhea; the other 15 patients were asymptomatic. In a recent study, Yeon et al reviewed patients' histological reports receiving PPIs who had no symptoms of diarrhea and matched the controls. The intraepithelial lymphocyte count was significantly higher in the PPI group than controls. They suggested the findings as an early stage of the disease even before the onset of the symptoms [21].
In a large retrospective study, celiac disease, IBS and thyroid diseases were found to have a higher occurrence in MC compared to controls [22]. The symptomatic overlap between IBS and microscopic colitis makes the diseases difficult to be diagnosed clinically and suggests that a colonoscopy is imperative [23]. Almost all the studies, which were trying to show the association of MC and IBS were made with patients who have diarrhea predominant IBS (IBS-D) [24-26]. In a recent study patients previously diagnosed as IBS reported $6.07 \%$ $\mathrm{MC}$ with $5.27 \%$ of $\mathrm{LC}$ and $0.8 \%$ of CC. While other authors found the incidence of CC $7.2 \%$ and LC $2.2 \%$ among the patients diagnosed as IBS $[25,27]$. There are few reports about the constipation predominant IBS and MC. Carmona-Sanchez et al reviewed 155 patients with IBS-D and 145 with IBS-C. Both groups were matched from the standpoint of age, gender ratio and time course of disease. MC was detected in 28 patients with IBS-D and in one with IBS-C (18\% vs. $0.7 \%, \mathrm{P}<$ $0.0001)$ [28].

Our case illustrates a rare condition of MC, without any symptoms of diarrhea and concomitant with constipation dominant IBS. Although lansoprazole is a widely prescribed drug for gastroesophageal reflux and peptic ulcer disease, the frequency of lansoprazole-associated MC is not well-estimated for subjects without symptoms of diarrhea. We think that the incidence of lansoprazole-associated MC is higher than known incidence.

\section{References}

1. Mohamed N, Marais M, Bezuidenhout J. Microscopic colitis as a missed cause of chronic diarrhea. World J Gastroenterol. 2011;17(15):1996-2002.

2. Veress B, Lofberg R, Bergman L. Microscopic colitis syndrome. Gut. 1995;36(6):880-886.

3. Hilmer SN, Heap TR, Eckstein RP, Lauer CS, Shenfield GM. Microscopic colitis associated with exposure to lansoprazole. Med J Aust. 2006;184(4):185-186.

4. Giardiello FM, Lazenby AJ, Bayless TM. The new colitides, Collagenous, lymphocytic, and diversion colitis. Gastroenterol Clin North Am. 1995;24(3):717-729.

5. Jessurun J, Yardley JH, Giardiello FM, Hamilton SR, Bayless TM. Chronic colitis with thickening of the subepithelial collagen layer (collagenous colitis): histopathologic findings in 15 patients. Hum Pathol. 1987;18(8):839-848.

6. Nomura E, Kagaya H, Uchimi K, Noguchi T, Suzuki S, Suzuki M, Onodera H, et al. Linear mucosal defects: a characteristic endoscopic finding of lansoprazole-associated collagenous colitis. Endoscopy. 2010;42(Suppl 2):E9-10.

7. Keszthelyi D, Jansen SV, Schouten GA, de Kort S, Scholtes B, Engels LG, Masclee AA. Proton pump inhibitor use is associated with an increased risk for microscopic colitis: a case-control study. Aliment Pharmacol Ther. 2010;32(9):1124-1128.

8. Beaugerie L, Pardi DS. Review article: drug-induced microscopic colitis - proposal for a scoring system and review of the literature. Aliment Pharmacol Ther. $2005 ; 22(4): 277-284$. 
9. Fernandez-Banares F, Esteve M, Espinos JC, Rosinach M, Forne M, Salas A, Viver JM. Drug consumption and the risk of microscopic colitis. Am J Gastroenterol. 2007;102(2):324-330.

10. Pardi DS, Smyrk TC, Tremaine WJ, Sandborn WJ. Microscopic colitis: a review. Am J Gastroenterol. 2002;97(4):794-802.

11. Bohr J, Tysk C, Eriksson S, Jarnerot G. Collagenous colitis in Orebro, Sweden, an epidemiological study 19841993. Gut. 1995;37(3):394-397.

12. Fernandez-Banares F, Salas A, Forne M, Esteve M, Espinos J, Viver JM. Incidence of collagenous and lymphocytic colitis: a 5-year population-based study. Am J Gastroenterol. 1999;94(2):418-423.

13. Erdem L, Yildirim S, Akbayir N, Yilmaz B, Yenice N, Gultekin OS, Peker O. Prevalence of microscopic colitis in patients with diarrhea of unknown etiology in Turkey. World J Gastroenterol. 2008;14(27):4319-4323.

14. van Boxel OS, Hagenaars MP, Smout AJ, Siersema PD. Sociodemographic factors influence use of proton pump inhibitors among users of nonsteroidal anti-inflammatory drugs. Clin Gastroenterol Hepatol. 2009;7(8):855-861.

15. Thomson RD, Lestina LS, Bensen SP, Toor A, Maheshwari Y, Ratcliffe NR. Lansoprazole-associated microscopic colitis: a case series. Am J Gastroenterol. 2002;97(11):2908-2913.

16. Mullin JM, Gabello M, Murray LJ, Farrell CP, Bellows J, Wolov KR, Kearney KR, et al. Proton pump inhibitors: actions and reactions. Drug Discov Today. 2009;14(1314):647-660.

17. Mullin JM, Valenzano MC, Whitby M, Lurie D, Schmidt JD, Jain V, Tully O, et al. Esomeprazole induces upper gastrointestinal tract transmucosal permeability increase. Aliment Pharmacol Ther. 2008;28(11-12):1317-1325.

18. Lewis SJ, Franco S, Young G, O'Keefe SJ. Altered bowel function and duodenal bacterial overgrowth in patients treated with omeprazole. Aliment Pharmacol Ther. 1996;10(4):557-561.

19. Wang N, Dumot JA, Achkar E, Easley KA, Petras RE, Goldblum JR. Colonic epithelial lymphocytosis without a thickened subepithelial collagen table: a clinicopathologic study of 40 cases supporting a heterogeneous entity. Am J Surg Pathol. 1999;23(9):1068-1074.

20. Goldstein NS, Bhanot P. Paucicellular and asymptomatic lymphocytic colitis: expanding the clinicopathologic spectrum of lymphocytic colitis. Am J Clin Pathol. 2004;122(3):405-411.

21. Yu YH, Han DS, Choi EY, Park HS, Jeong JY, Eun CS, $\mathrm{Oh} \mathrm{YH}$, et al. Is use of PPIs related to increased intraepithelial lymphocytes in the colon? Dig Dis Sci. 2012;57(10):2669-2674.

22. Kao KT, Pedraza BA, McClune AC, Rios DA, Mao YQ, Zuch RH, Kanter MH, et al. Microscopic colitis: a large retrospective analysis from a health maintenance organization experience. World J Gastroenterol. 2009;15(25):3122-3127.

23. Abboud R, Pardi DS, Tremaine WJ, Kammer PP, Sandborn WJ, Loftus EV, Jr. Symptomatic overlap between microscopic colitis and irritable bowel syndrome: a prospective study. Inflamm Bowel Dis. 2013;19(3):550-553.

24. Limsui D, Pardi DS, Camilleri M, Loftus EV, Jr., Kammer PP, Tremaine WJ, Sandborn WJ. Symptomatic overlap between irritable bowel syndrome and microscopic colitis. Inflamm Bowel Dis. 2007;13(2):175-181.

25. Stoicescu A, Becheanu G, Dumbrava M, Gheorghe C, Diculescu M. Microscopic colitis - a missed diagnosis in diarrhea-predominant irritable bowel syndrome. Maedica (Buchar). 2012;7(1):3-9.

26. Olesen M, Eriksson S, Bohr J, Jarnerot G, Tysk C. Microscopic colitis: a common diarrhoeal disease. An epidemiological study in Orebro, Sweden, 1993-1998. Gut. 2004;53(3):346-350.

27. Tavakoli H, Esmaili FS, Emami MH, Mahzoui P, Haghdani $\mathrm{S}$. Is microscopic colitis a missed diagnosis in diarhea predominant irritable bowel syndrome? J of Research in Medical Sciences. 2008;13(4);166-174.

28. Carmona-Sanchez R, Carrera-Alvarez MA, Perez-Aguilar RM. [Prevalence of microscopic colitis in patients with irritable bowel syndrome with diarrhea predominance]. Rev Gastroenterol Mex. 2011;76(1):39-45. 